\title{
Properties of Asphalt Mixtures Using Reclaimed Asphalt Containing Polymer-Modified Binder and Technicoeconomical Considerations of Their Use
}

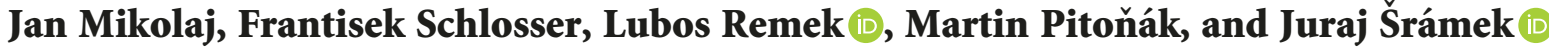 \\ Department of Construction Management and Technology, University of Zilina, Zilina 010 01, Slovakia \\ Correspondence should be addressed to Lubos Remek; lubos.remek@fstav.uniza.sk
}

Received 8 July 2019; Revised 4 September 2019; Accepted 19 September 2019; Published 17 October 2019

Guest Editor: Chaoqun Zhang

Copyright (c) 2019 Jan Mikolaj et al. This is an open access article distributed under the Creative Commons Attribution License, which permits unrestricted use, distribution, and reproduction in any medium, provided the original work is properly cited.

\begin{abstract}
The article summarises findings from laboratory testing of asphalt mixtures using reclaimed asphalt containing polymer-modified binder and subsequent technicoeconomical considerations of their use in pavement management system. Tested mixtures had $0 \%$, $15 \%$, and $40 \%$ content of reclaimed asphalt (RA) containing polymer-modified bitumen (PMB) obtained by milling from surfacing layers of existing PA, AC11, and SMA11 pavement layers. A complete description of these mixtures is given, and testing methods used are described. The mixtures were tested for air void content, ITSR water sensitivity test, plastic deformation wheel tracking test, stiffness of the tested mixtures, and two-point bending test to ascertain fatigue. Concise and succinct conclusions from laboratory testing are derived and used as an input in the second part of the article. It is found that the addition of RA containing PMB increased stiffness modulus of the final mixture, which increases resistance to plastic deformation and leads to higher brittleness at low temperatures. It is found that virgin PMB also increases fatigue resistance as opposed to PMB content from reclaimed materials. In the second part of the article, findings from laboratory testing are addressed in the context of their practical use in pavement management. The key element identified, having a direct impact on pavement performance models, was the stiffness modulus for mixtures with different PMB-reclaimed asphalt contents. A method is described to evaluate pavement construction properties related to wearing course materials via the pavement performance model. Practical use of this method is described and applied in a case study. In this case study, the proposed method is used to evaluate the issues regarding practical use of asphalt mixtures with different ratios of reclaimed asphalt containing PMB and economic implications of their use. It is found that pavement performance of surfacing mixtures with reclaimed asphalt containing PMB is significantly better for plastic deformation at the cost of earlier initiation and progression of surface distress due to cracking and potholing. This paper suggests that due to cracking and potholing, periodic maintenance costs increase for pavements with reclaimed asphalt material containing PMB; however, they are outweighed by lower procurement cost and longer life expectancy due to slower plastic deformation of the pavement.
\end{abstract}

\section{Introduction}

In the past decades, polymer-modified asphalt was used quite extensively in civil engineering throughout the world, mostly for motorway pavements and premium pavements. Originated in the $80 \mathrm{~s}$, the production, quality control, and utilization of modified bitumen via polymer became the norm for pavements subject to high traffic loading during their life cycle. The addition of polymers increases the durability and functionality of these pavements resulting in high bearing capacity. [1] At present, many of these pavements are at the end of their life cycle, and reclaimed asphalt (RA) that contains polymer-modified bitumen (PMB) is readily available. This presents a potential to provide a premium binder in new asphalt mixtures for new pavements and pavement repair and reconstruction. In addition, with ecological concerns and atmosphere changes, it is desirable to limit the production of new polymer with reuse of material that would other way end up in a landfill. This "RA containing PMB" material is thus considered an asset with high practical and environmental potential. [2]. 
Practical application of RA containing PMB material bears its own set of challenges and considerations. In the past, in labo testing of these materials suggested some adverse material properties $[3,4]$ accompanying the desired increase in stiffness modulus and better fatigue performance. In order to consider the practical application of RA containing $\mathrm{PMB}$, a set of mixtures with $0 \%, 15 \%$, and $40 \%$ of PMB RA content were subjected to laboratory testing. The mixtures were tested for air void content, ITSR water sensitivity test, plastic deformation wheel tracking test, stiffness of the tested mixtures, and two-point bending test to ascertain fatigue. This showed proportionally how the PMB RA content influences the material properties of finished mixtures. These results need to be translated via the pavement performance model [5] into life cycle analysis of asphalt surfacing. Two parameters were modelled in the life cycle analysis, the transversal unevenness (RUT) as a practical indicator of pavement plasticity and the surface distress represented by cracking. Cracking was chosen as all the other surface defects except ravelling are initiated by cracking. The hypothesis was that ascertained material properties for different PMB RA content mixtures would translate into different pavement performance. This was confirmed by a case study that compared three scenarios where the wearing course made with $0 \%, 15 \%$, and $40 \%$ of PMB RA content was a sole variable.

\section{Evaluated Asphalt Mixtures and Their Compounding Materials}

2.1. Evaluated Asphalt Mixtures. Three different types of asphalt mixtures were selected for use in wearing courses: SMA 11, AC 11, and PA 8. These mixtures were designed and produced for in labo testing, aiming to ascertain their performance with different RA content ratios. The binder in RA was SBS polymer-modified bitumen and PGB. The RA content ratios were $0 \%, 15 \%$, and $40 \%$. Table 1 shows the mixtures designed for testing. As seen from the table, PGB with $15 \%$ RA was not considered as it would only dilute the polymer to a level where no effect of the polymer could be expected.

2.2. Virgin Binders. Four virgin binders were used to produce the mixtures with RA. Two paving-grade bitumen and also two SBS polymer-modified bitumen, i.e., four virgin binders, were used to produce tested mixtures:
(i) Q8 - straight run bitumen, paving grade 70/100
(ii) KR-PMB $10 \%$ of D0243 SBS in B160/220 bitumen
(iii) 70/100-straight run bitumen
(iv) 90/150-75-SBS polymer-modified bitumen

2.3. Aggregate and Fillers. Common aggregate and fillers were used in the test. Aggregate and fillers used into the individual mixtures are described in Table 2. Cellulose fibres were added in SMA 11 and AC 11; this is a common practice
TABle 1: Mixtures for testing.

\begin{tabular}{lcccccc}
\hline \multirow{2}{*}{ RA content } & \multicolumn{2}{c}{ SMA 11} & \multicolumn{2}{c}{ PA 8} & \multicolumn{2}{c}{ AC 11} \\
& PGB & PMB & PGB & PMB & PGB & PMB \\
\hline $0 \%$ & $\checkmark$ & $\checkmark$ & $\checkmark$ & $\checkmark$ & $\checkmark$ & $\checkmark$ \\
$15 \%$ & - & $\checkmark$ & - & $\checkmark$ & - & $\checkmark$ \\
$40 \%$ & $\checkmark$ & $\checkmark$ & $\checkmark$ & $\checkmark$ & $\checkmark$ & $\checkmark$ \\
\hline
\end{tabular}

as fibres are shown to reduce the stress level of asphalt mortar significantly [6].

2.4. Reclaimed Asphalts. Three reclaimed asphalts, RAN, RAS, and RAD, were obtained by milling from surfacing layers of existing pavements (PA, AC 11, and SMA 11) and subsequent crushing. Table 3 shows detailed information about these reclaimed asphalts.

\section{Mixture Preparation and Testing Program}

3.1. Mixture Preparation. The mixtures were produced following requirements/recommendation in EN 12697$35+$ A1 [7]. All samples were prepared following the exact same process. The process was the same for all samples and it is shown in Figures 1-3. The mixtures were produced in the thermostatically controlled shaft mixer. The following mixing steps and times were applied to achieve a homogeneous mixture:

(1) Aggregates together with fibres (fibres preheated to $110^{\circ} \mathrm{C}$ ) were poured in the laboratory mixer and mixed for $30 \mathrm{~s}$

(2) RA was added and mixed for $30 \mathrm{~s}$

(3) Virgin binder was added and mixed for $90 \mathrm{~s}$

(4) Finally, filler was added and mixed for $60 \mathrm{~s}$

3.2. Testing Program. Five tests (Table 4) were performed on the PA 8, SMA 11, and AC 11 sample mixtures.

3.2.1. $V_{m}$ Test. Air void content test performed following EN 12697-8 [8], evaluated by EN 12697-5, volumetric procedure A-with water [9], and EN 12697-6 [10] to assess the bulk density of the compacted asphalt procedure B-saturated surface dry (SSD) and procedure D-by dimensions.

Test conditions: the bulk density of the compacted specimen.

(i) 4 test specimens

(ii) Sample compaction-impact compactor, $2 \times 50$ blows

(iii) SMA 11 and AC 11 mixtures-the procedure B-SSD dry

(iv) PA8 mixtures-the procedure $\mathrm{D}$-by dimensions

The maximum density of the mixture:

(i) 2 test specimens

(ii) Procedure $\mathrm{A}-\mathrm{a}$ volumetric procedure with water 
TABLe 2: Aggregate and fillers used for different mixtures.

\begin{tabular}{|c|c|c|c|c|c|c|c|c|}
\hline \multicolumn{3}{|c|}{ SMA 11} & \multicolumn{3}{|c|}{ PA8 } & \multicolumn{3}{|c|}{ AC 11} \\
\hline Aggregate $(\mathrm{mm})$ & Filler & Fibres & Aggregate & Sand & Filler & Fibres & Aggregate & Filler \\
\hline $\begin{array}{l}8 / 11,2 \\
5,6 / 8\end{array}$ & $\begin{array}{c}\text { Limestone } \\
\text { Hydrated lime }\end{array}$ & $\begin{array}{c}\text { Cellulose } \\
5,6 / 8\end{array}$ & $8 / 11,2$ & Crushed sand $<2 \mathrm{~mm}$ & Wigro $60 \mathrm{~K}$ & $\begin{array}{c}\text { Cellulose } \\
4 / 8\end{array}$ & $8 / 11,2$ & Limestone \\
\hline $\begin{array}{l}2 / 5,6 \\
0 / 2\end{array}$ & & & $\begin{array}{c}4 / 5,6 \\
2 / 4\end{array}$ & & & & $2 / 4$ & \\
\hline
\end{tabular}

Table 3: Aggregate and fillers used for different mixtures.

\begin{tabular}{|c|c|}
\hline RAN & $\begin{array}{l}\text { PMB 40/100-65 HD 7-year-old reclaimed wearing } \\
\text { course of double porous asphalt. }\end{array}$ \\
\hline RAS & $\begin{array}{l}\text { Wearing course of dense AC } 11 \text { motorway surfacing } \\
\text { build in 1996. SBS polymer-modified bituminous } \\
\text { binder with original name Apollobit MCA-S. }\end{array}$ \\
\hline RAD & $\begin{array}{c}\text { Stone mastic asphalt (SMA 11) from motorway } \\
\text { constructed in 1989. SBS polymer-modified } \\
\text { bituminous binder Caribit Plus } 85 .\end{array}$ \\
\hline
\end{tabular}

Bulk density of the compacted asphalt accordingly is determined from its weight and bulk. The weight of the test sample is determined by weighing it in the air. The air void content is then calculated by equation (1).

$$
V_{m}=\frac{\rho_{m}-\rho_{b}}{\rho_{m}} \times 100
$$

where $V_{m}$ is the air void content [\%]; $\rho_{m}$ is the maximum density of asphalt mixture $\left[\mathrm{kg} / \mathrm{m}^{3}\right]$; and $\rho_{b}$ is the bulk density of the compacted asphalt mixture $\left[\mathrm{kg} / \mathrm{m}^{3}\right]$.

3.2.2. ITSR Water Sensitivity. Test was performed following EN 12697-12 method A [11]. Method A uses the indirect tensile strength of cylindrical specimens of bituminous mixtures. A set of cylindrical test specimens is divided into two equally sized subsets and conditioned. One subset is maintained dry at room temperature, while the other subset is saturated and stored in water at elevated conditioning temperature. After conditioning, the indirect tensile strength of each of the two subsets is determined at a defined test temperature, depending on the grade of bitumen. The ratio of the indirect tensile strength of the water conditioned subset compared to that of the dry subset is determined and expressed in percent.

Test conditions: six specimens were prepared for each combination of virgin materials and RA using $2 \times 35$ strikes of the compactor. The diameter of prepared specimens was $101.6 \pm 0.1 \mathrm{~mm}$ and height was $63.5 \pm 2.5 \mathrm{~mm}$. The specimens were divided into two subsets according to bulk density and height and conditioned before testing. The dry subset was stored at temperature of $20 \pm 5^{\circ} \mathrm{C}$. The wet subset after saturation in the vacuum container was stored in a water bath at $40 \pm 1^{\circ} \mathrm{C}$ for a period of 68 to 72 hours. The indirect tensile strength test of each specimen was determined at a test temperature of $25 \pm 2^{\circ} \mathrm{C}$. The indirect tensile strength ratio was calculated using average indirect tensile strength of the wet and dry subsets.
3.2.3. $W T S_{A I R}$ and $P R D_{A I R}$. Plastic deformation wheel tracking test in accordance with EN 12697-22 + A1 [12]. Test equipment and test conditions were selected according to EN 13108-20, Annex D [13]. The susceptibility of asphalt mixtures to deformation is evaluated by measuring the track depth produced by repeated passes of the loaded wheel at a constant temperature. The device is started up. After a specified number of 1,000,3,000, and 10,000 load cycles, and even after 30, 100, 300, and 100,000 load cycles, the instrument is stopped and the track depth measured at 15 predetermined points. The number of cycles does not include running-in cycles. During the test, the temperature in the test sample is maintained at a set temperature of $\pm 2^{\circ} \mathrm{C}$. The sample test is terminated after the required number of load cycles has been performed or if the average track depth exceeds $18 \mathrm{~mm}$. This test is appropriate for asphalt concrete, very thin layer asphalt concrete, hot-rolled asphalt, stone mastic asphalt, and porous asphalt mixtures.

Test conditions:

(i) A small size device

(ii) Procedure B

(iii) Conditioning and testing-in the air at the test temperature of $50 \pm 1^{\circ} \mathrm{C}$

(iv) 10,000 load cycles

(v) 2 test specimens for each test-slabs with dimensions of $260 \mathrm{~mm} \times 300 \mathrm{~mm}$ and thickness of $40 \mathrm{~mm}$

Two test samples were prepared in the laboratory for each combination of virgin materials and RA using compactor. The rut depth was continuously recorded, and a relationship between the rut depth and the number of load cycles was charted. After testing, a wheel tracking slope WTS $_{\text {AIR }}$ was calculated from the rut depth curve (the values at 5,000 and 10,000 load cycles were used), and a proportional rut depth $\mathrm{PRD}_{\mathrm{AIR}}$ at 10,000 cycles was determined.

3.2.4. Stiffness. Stiffness of the tested mixtures was performed according to EN 12697-26, method C [14]. Samples are deformed in their linear range, under repeated loads or controlled strain rate loads. From the measured force and deformation signal, amplitudes of the stress and strain and the phase angle between both are calculated. Based on measured stress and strain, desired modulus can be calculated. Method $\mathrm{C}$ describes measuring the resilient stiffness of bituminous mixtures using an indirect tensile test. The method is applicable to cylindrical specimens of various diameters and thickness manufactured in the laboratory or cored from a 

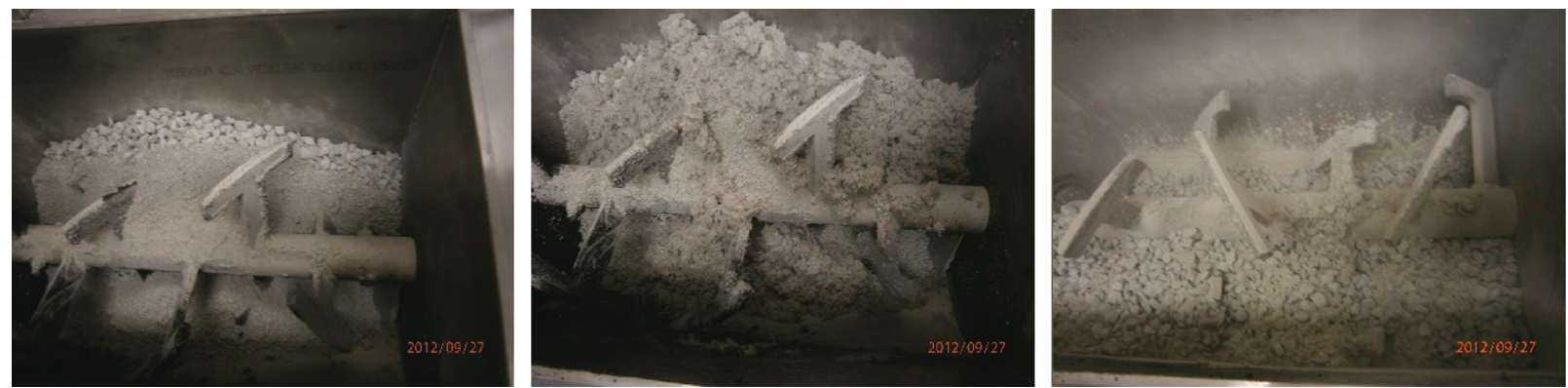

FIGURE 1: Step 1-mixing of aggregates and fibres [2].
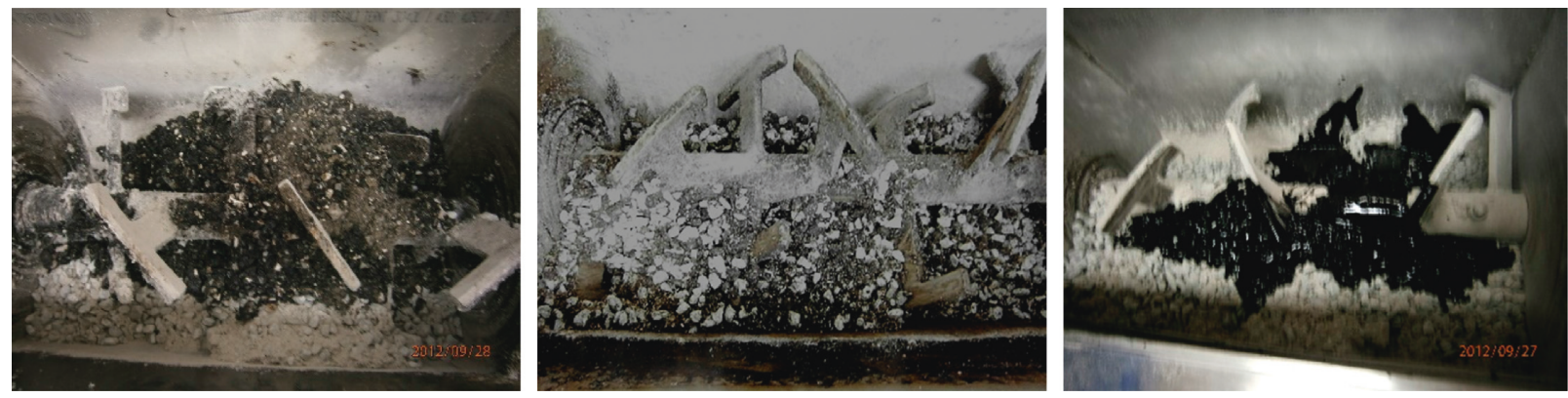

Figure 2: Step 2-addition of RA, step 3-addition of virgin binder [2].
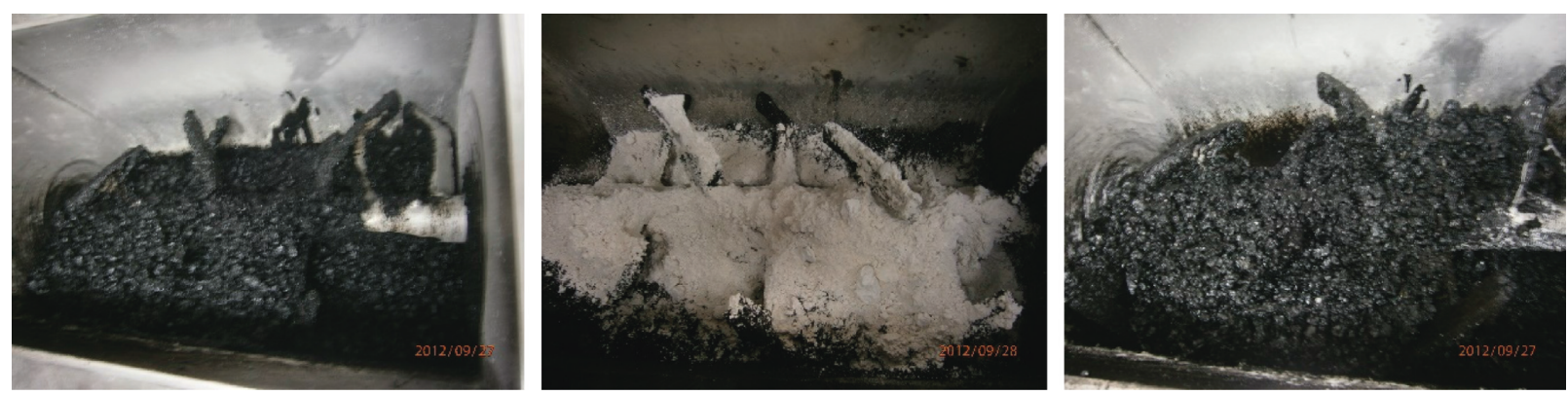

FIgURE 3: Step 4-addition of filler into the mixture [2].

TABLE 4: Testing program: mixture design: percentage of various components in the five mixtures of PA 8.

\begin{tabular}{lccc}
\hline Test & \multicolumn{3}{c}{ Mixture } \\
& PA 8 & SMA 11 & AC 11 \\
\hline$V_{\mathrm{m}}$ test & $\checkmark$ & $\checkmark$ & $\checkmark$ \\
ITSR water sensitivity $_{\text {WTS }}$ aIR and PRD & $\checkmark$ & $\checkmark$ & $\checkmark$ \\
Stiff & $\checkmark$ & $\checkmark$ & $\checkmark$ \\
Fatigue & $\checkmark$ & $\checkmark$ & $\checkmark$ \\
\hline
\end{tabular}

road layer. This test is appropriate only for asphalt concrete, hot-rolled asphalt, and stone mastic asphalt mixtures.

Test conditions:

(i) 6 specimens with a diameter of $101.6 \pm 0.1 \mathrm{~mm}$ and a height of $63.5 \pm 2.5 \mathrm{~mm}$

(ii) 4 temperatures $0^{\circ} \mathrm{C},+10^{\circ} \mathrm{C},+15^{\circ} \mathrm{C},+20^{\circ} \mathrm{C}$, and $+30^{\circ} \mathrm{C}$

(iii) Device-universal servohydraulic testing machine
Six specimens were prepared in the impact compactor $(2 \times 50$ impacts $)$ for each combination of virgin materials and RA. After conditioning to the test temperature, the sample was placed to LVDT alignment jig. LVDT sensors were set up. 10 conditioning pulses were applied after entering the input data needed for measurement (high, diameter, Poisson, and horizontal diametric deformation). Five load pulses were applied on the sample, the variation of applied load and horizontal diametric deformation with time were measured and recorded, and load area factor was determined. The sample was rotated by 90 degrees, reconditioned, and subjected to another set of five load pulses.

3.2.5. Two-Point Bending Test to Ascertain Fatigue. Performed on trapezoid specimens with controlled displacement according to EN 12697-24 [15]. Two-point bending test on trapezoidal-shaped specimens (2PB-TR) characterizes the behaviour of bituminous mixtures under 
fatigue loading with controlled displacement by two-point bending using trapezoidal-shaped specimens. The method can be used for bituminous mixtures with a maximum aggregate size of up to $20 \mathrm{~mm}$ on specimens prepared in a laboratory or obtained from road layers with a thickness of at least $40 \mathrm{~mm}$. For mixtures with an upper size D between $20 \mathrm{~mm}$ and $40 \mathrm{~mm}$, the test can be performed using the same principle but with adapter specimen sizes. For a given frequency of sinusoidal displacement, the method shall be carried out on several elements tested in a ventilated atmosphere at a controlled temperature. This test is appropriate only for asphalt concrete and stone mastic asphalt mixtures.

Test conditions:
(i) 18 specimens
(ii) Temperature $+10^{\circ} \mathrm{C}$
(iii) Frequency of $25 \mathrm{~Hz}$.

The trapezoidal-shaped specimens for the test were sawed from slabs made in laboratory. The tests were performed at the temperature of $+10^{\circ} \mathrm{C}$ and the frequency of $25 \mathrm{~Hz}$. Eighteen specimens were tested for each of the $0 \%$, $15 \%$, and $40 \%$ RA PMB mixtures. Controlled displacement was applied with values approximately regularly spaced on a logarithmic scale and also to have results for number of cycles to failure criterion $N \leq 10^{6}$ and $N \geq 10^{6}$. The fatigue line was determined in a bilogarithmic system as a linear regression of fatigue life versus amplitude levels. The strain $\varepsilon_{6}$ corresponding to an average of $10^{6}$ cycles and the slope of the fatigue line $1 / \mathrm{b}$ were determined. The estimation of the residual standard deviation and the quality index $\Delta \varepsilon_{6}$ were subsequently calculated.

\section{Results and Discussion}

Complete testing results and discussion are available in [2]. For the practical application of these mixtures in pavement construction, the most relevant results were identified as follows:

(1) No rutting was achieved for all polymer-modified binders during the wheel tracking test.

(2) The mixture without RA showed a significant amount of rutting. The mixture with RA containing PMB showed a better performance concerning rutting, and the ratio of RA increased resistance to rutting. This might indicate an advantage of the remaining SBS in the binder. However, it is worth noting that this could also be the effect of the aged binder, which has a higher softening point.

(3) The mixtures with RA containing PMB have a higher stiffness modulus compared to the mixtures without RA. This makes these mixtures more brittle at low temperatures, and the advantage to this would be a higher bearing capacity. Ideal balance between stiffness and chance of brittleness varies for different temperature conditions. Increased brittleness can be verified cracking at low-temperature testing [16].
(4) The mixture with $40 \%$ RA containing PMB showed worse fatigue parameters compared to the mixture without RA containing PMB, which confirmed expectations based on [17]. On the contrary, the mixture with virgin $\mathrm{PMB}$ was the most fatigue resistant. The addition of RA decreased fatigue performance.

4.1. Pavement Performance Considerations and Economic Implications. Conclusions from testing of asphalt mixtures with RA content in the previous section provide good insight into in labo performance of these pavement materials. However, it is hard to translate these findings into measurable indicators impacting the decision-making process of a road administrator, i.e., their practical use. The key element we identified having a direct impact on pavement performance models was the stiffness modulus for mixtures with different RA content. Asphalt with a harder blended binder had higher stiffness modulus and vice versa as was identified in [2] and is presented in Figures 4 and 5.

Asphalt with a harder blended binder having higher stiffness modulus could be an advantage since an increased stiffness translates into a higher bearing capacity. However, if the stiffness is very high, this could lead to brittleness at low temperatures. Therefore, it is necessary to find a balance between desired stiffness and risk of brittleness, while taking into account temperature conditions at the locality where the particular mixture is to be used. This can be verified by low-temperature cracking and properties' testing.

The fatigue parameters also have a significant impact on pavement management and pavement performance model; we advise to look into $[18,19]$ and foremost $[20]$ to see how these can be utilised to calculate residual bearing capacity, service life, and appropriate overlay thickness.

\subsection{Stiffness Modulus Influence on Pavement Performance.} To ascertain the impact of stiffness modulus on pavement performance, we identified the model and evaluated two characteristic parameters:

4.2.1. RUT. The transversal unevenness is the best practical indicator of pavement plasticity. Longitudinal unevenness IRI (international roughness index), while heavily influenced by pavements plasticity, is a composite parameter influenced by other parameters such as potholing, cracking, and variation of RUT depth [21].

4.2.2. Surface Distress. Various methods may be used to assess pavement distress such as pavement distress index and surface damage percentages. Surface distress relates to carriageway damage from potholing, wide structural cracks, thermal cracks, ravelled material, and edge break. For the following evaluation, we focussed on cracking, its initiation, progress into wide structural cracks, and potholing. These defects will impact surface distress the most; thus, the role of 


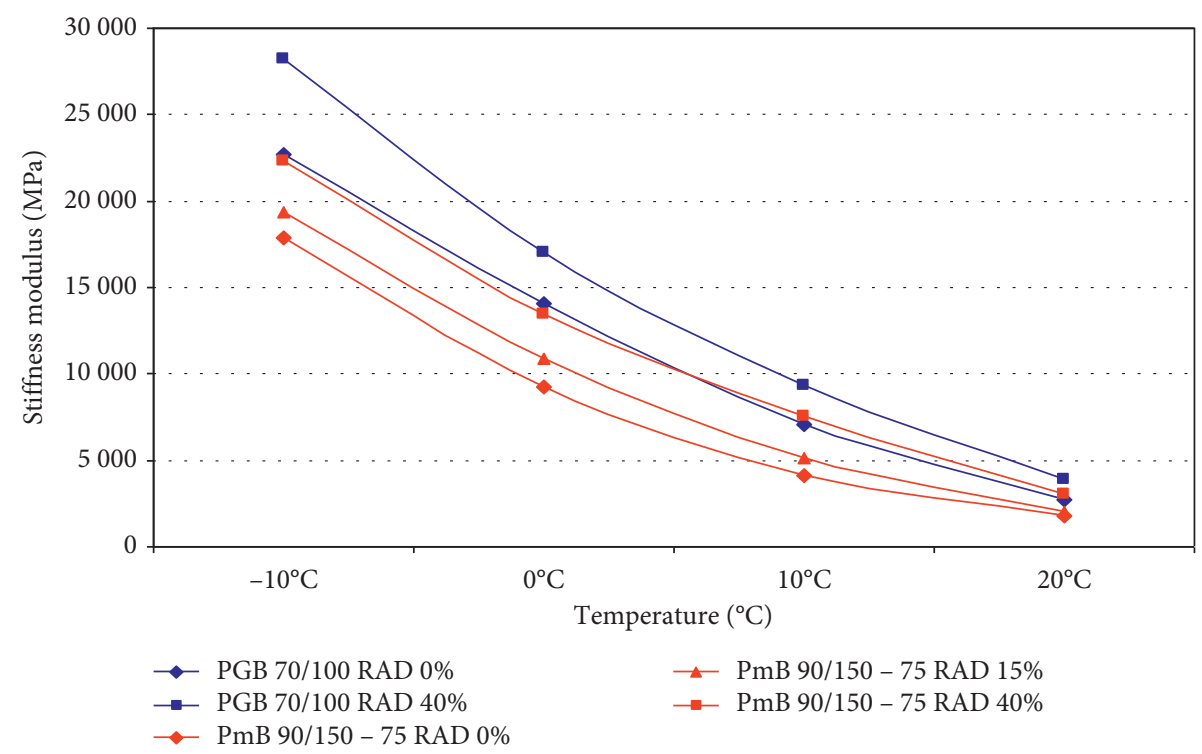

Figure 4: Stiffness modulus of SMA mixtures with different content of RAD.

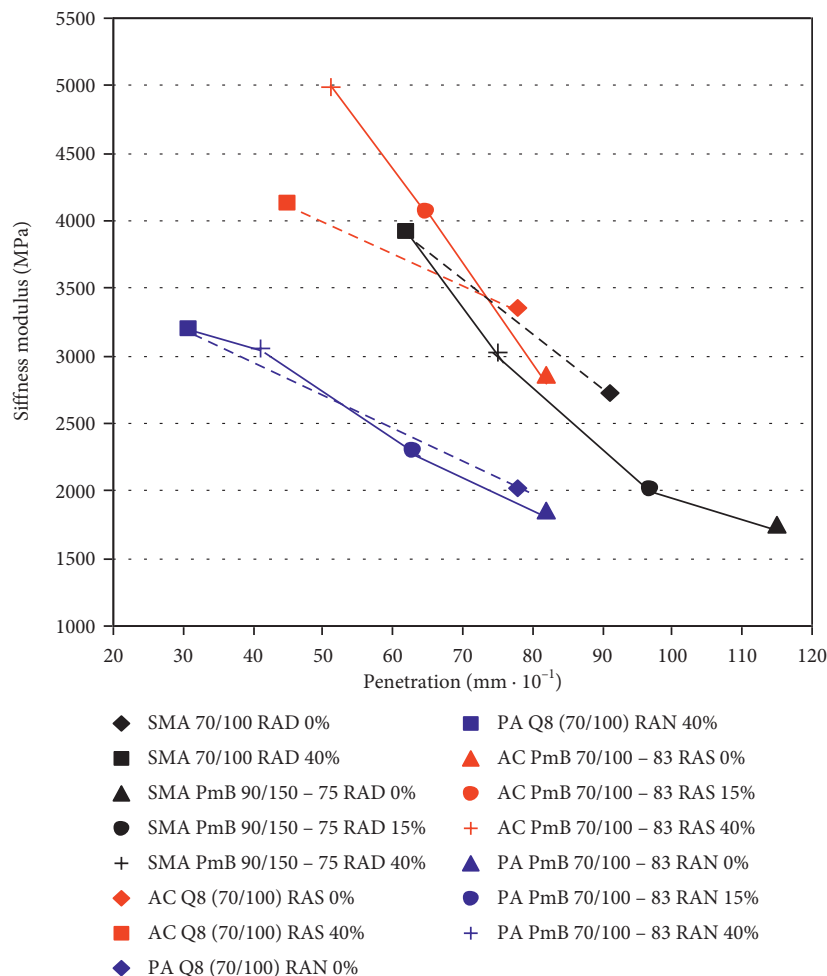

Figure 5: Relationship between penetration and stiffness modulus for all mixtures at a temperature of $20^{\circ} \mathrm{C}$.

stiffness modulus in the initiation and progression of these distresses was studied.

4.3. Modelling Method. Road deterioration ensues as a result of traffic loading and environmental/climatic effects. The paving material fatigue manifests itself as pavement deformation (unevenness) and defects (cracks, potholes, ravelling, loss of skid resistance, etc.). The ability of the pavement structure and material to withstand these adverse effects is called pavement performance. Pavement performance model (PPM) is a mathematical description of road deterioration process, and, as such, it is a crucial input for decision-making known generally as pavement management systems.

Pavement performance model on which the impact of stiffness modulus of the surfacing layer will be tested in the following case study is based on three major studies: 
Riley and Bennet [5], which is based on Paterson [22], Watanada et al. [23], and NDLI [24].

The final model is described in [5] but was further amended to fix further issues mostly by LCPC, TRL, Riley Partnership, ARRB, and UoB. The equations presented in this subchapter are an excerpt of the ISOHDM study [25]. This model is utilised in the World Bank's Highway Design and Management tool.

4.3.1. Structural Cracking Model: Initiation. Cracking initiation is said to occur when $0.5 \%$ of the surface area is cracked [25]. Initiation of structural cracking depends on whether it is an original surfacing or an overlay. For our purpose, we model an original surfacing for which crack initiation starts based on equation (2).

$$
\mathrm{ICA}=K_{\text {cua }}\left\{\mathrm{CDS}^{2} a_{0} \exp \left[\begin{array}{c}
a_{1} \mathrm{HSE}+a_{2} \log _{e} \mathrm{CMOD} \\
+a_{3} \log _{e} \mathrm{DEF}+a_{4}(\mathrm{YE} 4)(\mathrm{DEF})
\end{array}\right]+\mathrm{CRT}\right\},
$$

where ICA: time to initiation of all structural cracks (years), CDS: construction defects indicator for bituminous surfacing, YE4: annual number of equivalent standard axles (millions/lane), SNP: average annual adjusted structural number of the pavement, DEF: mean Benkelman beam deflection in both wheel paths $(\mathrm{mm})$, CMOD: resilient modulus of sub-base (GPa) (in the range between 0 and $30 \mathrm{GPa}$ for most stabilised bases), HSE: MIN [100, thickness of the surfacing layer], $K_{\text {cua }}$ : calibration factor for initiation of all structural cracking, and CRT: crack retardation time due to maintenance (years); $a_{0}-a_{4}$ : default coefficient values for initiation of structural cracking models (for SMA on stabilised base $a_{0}=1.12, a_{1}=0.035, a_{2}=0.371, a_{3}=-0.418$, and $\left.a_{4}=-2.87\right)$.

4.3.2. Structural Cracking Model: Progression. The model for the progression of cracking is given in equation (3).

$$
\mathrm{dACA}=K_{\mathrm{coa}}\left[\frac{\mathrm{CRP}}{\mathrm{CDS}}\right] z_{A}\left[\left(z_{A} a_{0} a_{1} \delta t_{A}+\mathrm{SCA}^{a 1}\right)^{1 / a 1}-\mathrm{SCA}\right],
$$

where dACA: incremental change in cracked area during the analysis year (\% of total carriageway area), Kcoa: calibration factor for cracking progression, CRP: retardation of cracking due to preventive treatment, CDS: construction defects indicator for bituminous surfacings, $\delta t_{A}$ : fraction of analysis year in which cracking progression applies, $a_{0}, a_{1}$ : default coefficient values for progression of structural cracking models (for SMA on stabilised base $a_{0}=2.13$ and $a_{1}=0.35$ ), SCA: MIN/[ACA $\left.a, 100-\mathrm{ACA}_{a}\right], z_{a}:-1$ if $\mathrm{ACA}_{a} \geq 50$, otherwise $z_{a}=1, \mathrm{ACA}_{a}$ : area of structural cracking.

4.3.3. RUT Model: Densification. The initial densification depends upon the degree of relative compaction of the base, sub-base, and subgrade layers. Relative compaction of the base, sub-base, and subgrade layers is given in equation (4), referred to as COMP. More information about COMP can be found in $[22,25]$. The initial densification can be calculated following equation (4).

$$
\mathrm{RDO}=K_{\mathrm{rid}}\left[a_{0}\left(\mathrm{YE}_{110^{6}}\right)^{\left(a_{1}+a_{2} \mathrm{DEF}\right)} \mathrm{SNP}^{a_{3}} \mathrm{COMP}^{a_{4}}\right],
$$

where RDO: rutting due to initial densification ( $\mathrm{mm}$ ), SNP: average annual adjusted structural number of the pavement, COMP: relative compaction (\%), $K_{\text {rid: }}$ calibration factor for initial densification, and $a_{0}-a_{4}$ : default coefficient values for initial densification model (for SMA on stabilised base $a_{0}=51740, a_{1}=0.09, a_{2}=0.384, a_{3}=-0.502$, and $\left.a_{4}=-2.30\right)$.

4.3.4. RUT Model: Progression. Plastic deformation following the initial densification is calculated by equation (5).

$$
\Delta \mathrm{RDPD}=K_{\mathrm{rpd}} \mathrm{CDS}^{3} a_{0} \mathrm{YE} \mathrm{Sh}^{a_{1}} \mathrm{HS}^{a_{2}},
$$

where $\triangle \mathrm{RDPD}$ : incremental increase in plastic deformation in the analysis year $(\mathrm{mm})$, Sh: speed of heavy vehicles $(\mathrm{km} /$ h), HS: total thickness of bituminous surfacing $(\mathrm{mm}), K_{\text {rpd: }}$ : calibration factor for plastic deformation, $a_{0}-a_{3}$ : default coefficient values for plastic deformation model (for SMA on stabilised base $a_{0}=0.3, a_{1}=3.27, a_{2}=-0.78$, and $a_{3}=71$ ).

4.4. Case Study. Three scenarios were designed to evaluate the performance of the surfacing layer with different RA content. The pavement is a motorway section required earthwork bearing capacity $E_{p, n}=45 \mathrm{MPa}$ designed for ESAL (Equivalent Standard Axle Load) of $20 \times 10^{6}$. Construction layers are shown in Figure 6. For special considerations when designing pavement where recycled materials are embedded, see [26].

The three scenarios differ in SMA wearing course of the pavement. The scenarios reflect the in labo testing of SMA mixture with $0 \%, 15 \%$, and $40 \%$ RA content:

(i) $0 \% \mathrm{RA}$ content in scenario 1

(ii) $15 \%$ RA content in scenario 2

(iii) $40 \%$ RA content in scenario 3

The RA content was simulated with the use of CDS (construction defect rating for bituminous surfacing). CDS for which values $>1.0$ make the pavement more plastic and values $<1.0$ make the pavement more brittle. The CDS values were calculated proportionally to stiffness modulus ascertained for SMA PMB mixtures in the material testing section.

The pavement was subjected in each scenario to AADT (annual average daily traffic) of 12,500 vehicles per lane. The characteristic vehicles in the vehicle fleet and traffic composition are shown in Table 5.

Climatic conditions would obviously have an impact on both RUT and surfacing distress. As running the calculation for different climate zones would add another layer of complexity, the study was performed only for semiarid cool climate zone shown in Table 6.

4.5. Pavement Performance. The test evaluated 20 years of the pavement life cycle for each scenario. The traffic intensity 


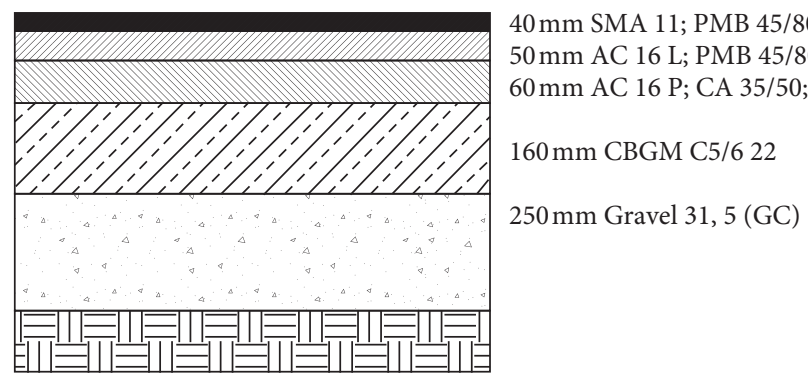

Figure 6: Case study pavement-material and thickness of layers.

TAвLE 5: Vehicle characteristic and traffic composition (for all scenarios).

\begin{tabular}{|c|c|c|c|c|c|c|c|c|}
\hline Name & Base type & $\begin{array}{c}\text { Passenger car space } \\
\text { equivalent }\end{array}$ & $\begin{array}{l}\text { No. of } \\
\text { wheels }\end{array}$ & $\begin{array}{l}\text { No. of } \\
\text { axles }\end{array}$ & $\begin{array}{l}\text { Tyre } \\
\text { type }\end{array}$ & ESAL & $\begin{array}{c}\text { Oper. weight } \\
(t)\end{array}$ & $\begin{array}{c}\text { Traffic share } \\
\% \\
\end{array}$ \\
\hline $\begin{array}{l}\text { Skoda Octavia } 1.6 \\
\text { MPI }\end{array}$ & Medium car & 1.00 & 4 & 2 & $\begin{array}{l}\text { Radial } \\
\text { ply }\end{array}$ & 0.00 & 1.59 & 74.6 \\
\hline Fiat Ducato & Light truck & 1.20 & 4 & 2 & $\begin{array}{l}\text { Radial } \\
\text { ply }\end{array}$ & 0.03 & 2.60 & 6.6 \\
\hline Iveco EuroCargo & Medium truck & 1.40 & 6 & 2 & $\begin{array}{l}\text { Radial } \\
\text { ply }\end{array}$ & 0.12 & 6.00 & 1.8 \\
\hline Volvo FM 9 & Heavy truck & 1.50 & 10 & 3 & $\begin{array}{l}\text { Radial } \\
\text { ply }\end{array}$ & 1.05 & 13.00 & 1.6 \\
\hline $\begin{array}{l}\text { Volvo FH } \\
12+\text { Schwarz }\end{array}$ & $\begin{array}{c}\text { Articulated } \\
\text { truck }\end{array}$ & 1.80 & 12 & 5 & $\begin{array}{l}\text { Radial } \\
\text { ply }\end{array}$ & 3.16 & 24.50 & 15.2 \\
\hline SOR C 9, 5 IVECO & Heavy bus & 1.50 & 6 & 2 & $\begin{array}{l}\text { Radial } \\
\text { ply }\end{array}$ & 2.12 & 15.00 & 0.2 \\
\hline
\end{tabular}

TABLE 6: Climatic characteristic (for all scenarios).

\begin{tabular}{lc}
\hline Temperature classification & Cool \\
\hline Mean temperature & $8^{\circ} \mathrm{C}$ \\
Avg. temperature & $20^{\circ} \mathrm{C}$ \\
Days $T>32^{\circ} \mathrm{C}$ & 12.1 \\
Moisture classification & Semiarid \\
Mean monthly precipitation & $64.1 \mathrm{~mm}$ \\
Moisture index & -36 \\
\hline
\end{tabular}

and climatic conditions remained constant in the experiment. During the 20-year period of pavement life cycle, the pavement accrued $4.39 \times 10^{6}$ ESA, i.e., almost quarter of its bearing capacity. Pavement performance model described in the previous chapter was applied for both RUT and SD. Pavement performance for each scenario for these two parameters is shown in Figures 7 and 8.

The shapes of pavement performance curves match the standard expectations. RUT is linear with initial densification effect in year 1. SD is exponential with initiation phases of varying length for each scenario (Figure 8). What strikes as obvious is the sharpness of the SD progression; this effect is due to the absence of periodic maintenance during the life cycle, i.e., no crack sealing and patching is performed resulting in rapid progress of surface damage.

4.6. Discussion and Economic Implications. It is important to realise that all effects and conclusions in this chapter will be more pronounced in warmer climate zones than that used for the case study (see Table 6); vice versa, for cooler climate zones, the difference between results may be less distinct, even reverse in extreme cool climate conditions.

The increased stiffness modulus for scenarios with SMA PMB including $15 \%$ and $40 \%$ of RA material show increased resiliency to plastic deformation resulting in $3 \mathrm{~mm}$ and $7 \mathrm{~mm}$ difference in RUT after 20 years of pavement's operation. This effect was expected based on [27], and is quite significant as the critical level on motorways are usually considered around $20 \mathrm{~mm}$ of RUT depth and the pavement is considered a valid candidate for repair as low as $10-15 \mathrm{~mm}$ based on different national standards.

The initiation of cracking takes place 2 and 7 years earlier for the scenarios with $15 \%$ and $40 \%$ of RA material, respectively, as seen in Figure 9. This is also significant, but the administrator can manage the progression of cracking and subsequent pothole progression with proper use of periodic maintenance. Due to this fact, the tests were run again with parodic maintenance applied.

As we can see, the initiation times of SD are not impacted, but the periodic maintenance curbs the SD to around $7.6 \%$ of damaged surface area, which needs to be repaired annually. This, of course, comes at a price of capital costs for the road administrator. If we consider the unit cost of $3,442 € / \mathrm{m}^{2}$ of crack sealing (calculated as personnel and material costs for sealing of $3 \mathrm{~mm}$ wide and 


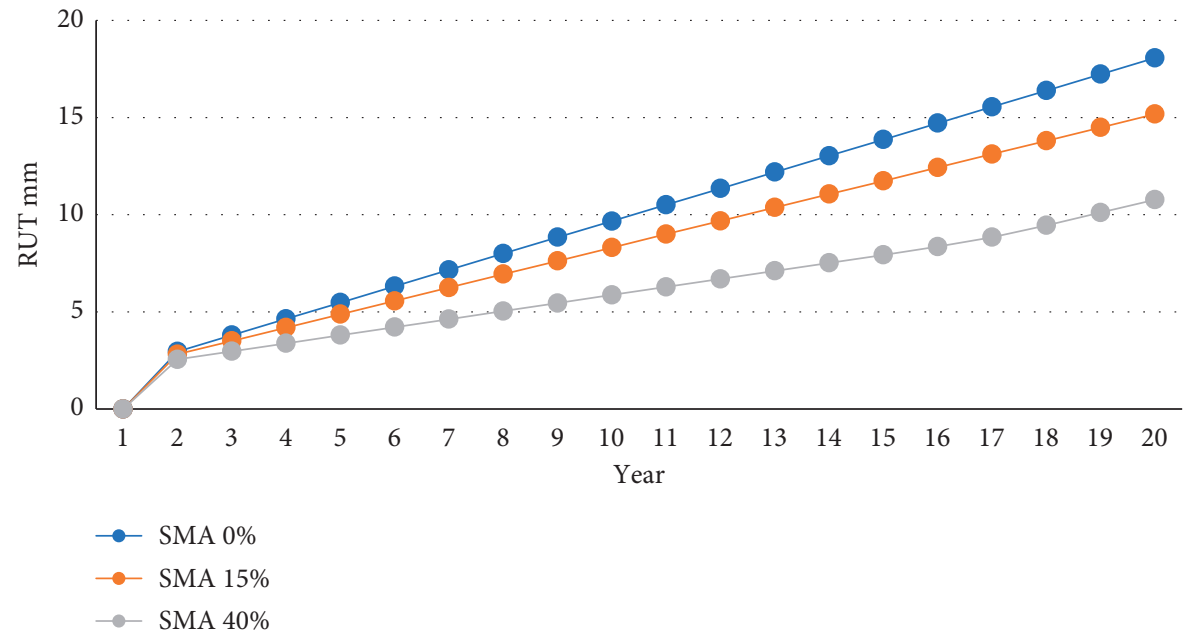

FIGURE 7: RUT pavement performance for SMA 11 PMB surfacing with 0\%, 15\%, and 40\% RA containing PMB.

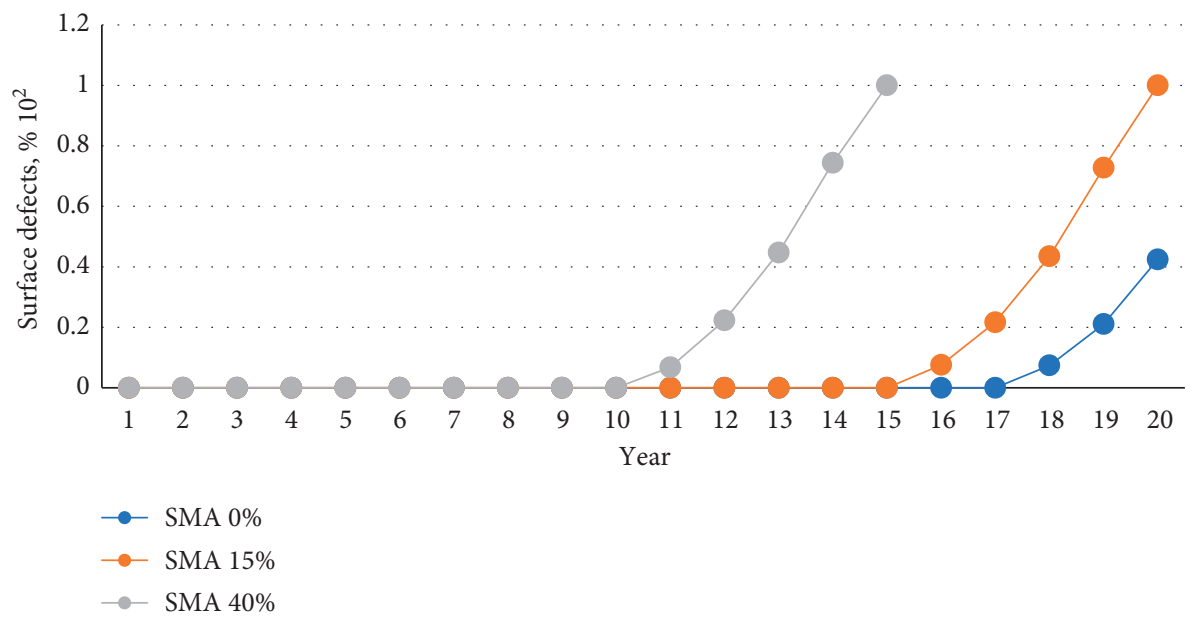

FIGURE 8: SD pavement performance for SMA 11 PMB surfacing with 0\%, 15\%, and 40\% RA containing PMBl-without periodic maintenance standard.

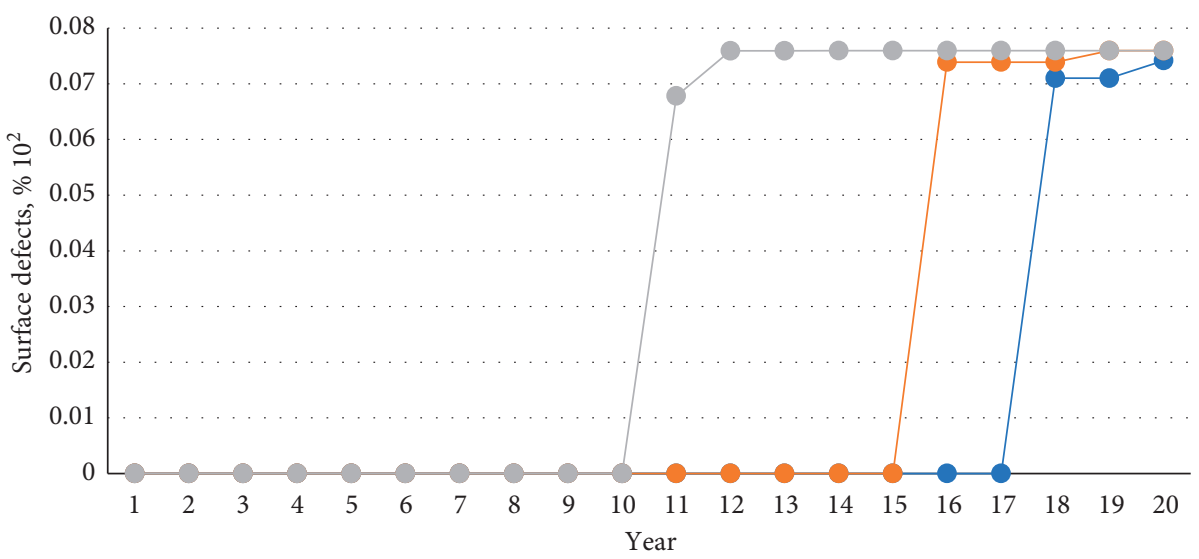

FIGURE 9: SD pavement performance for SMA 11 PMB surfacing with $0 \%, 15 \%$, and 40\% RA containing PMB-periodic maintenance standard applied. 
TABLE 7: Periodic maintenance costs for each scenario with periodic maintenance standard applied, $€ / \mathrm{m}^{2}$.

\begin{tabular}{|c|c|c|c|}
\hline \multicolumn{4}{|c|}{ Periodic maintenence costs (crack sealing + patching) } \\
\hline \multirow{2}{*}{ Year } & \multicolumn{3}{|c|}{ Scenario } \\
\hline & SMA 11 PMB $0 \%$ & SMA 11 PMB 15\% RA & SMA 11 PMB $40 \%$ RA \\
\hline 12 & 0 & 0 & 0.06 \\
\hline 13 & 0 & 0 & 0.04 \\
\hline 14 & 0 & 0 & 0.04 \\
\hline 15 & 0 & 0 & 0.04 \\
\hline 16 & 0 & 0 & 0.04 \\
\hline 17 & 0 & 0.06 & 0.04 \\
\hline 18 & 0 & 0.04 & 0.04 \\
\hline 19 & 0.06 & 0.04 & 0.04 \\
\hline 20 & 0.04 & 0.04 & 0.04 \\
\hline
\end{tabular}

TABLE 8: Estimated financial savings for procurement of asphalt mixtures with different ratios of RA containing PMB.

\begin{tabular}{|c|c|c|c|c|c|}
\hline Nominal RAD \% & $0 \% \mathrm{RAD}$ & $40 \% \mathrm{RAD}$ & $0 \% \mathrm{RAD}$ & $15 \%$ RAD & $40 \% \mathrm{RAD}$ \\
\hline Virgin binder type & \multicolumn{2}{|c|}{$\begin{array}{c}70 / 100 \\
\text { SV } 12135 \\
\text { Straight run paving grade } \\
\text { bitumen }\end{array}$} & \multicolumn{3}{|c|}{$\begin{array}{c}\text { 90/150-75 } \\
\text { SV } 12129 \\
\text { Polymer-modified bitumen }\end{array}$} \\
\hline $\begin{array}{l}\text { Virgin binder \% } \\
\text { Estimated financial savings \% }\end{array}$ & $\begin{array}{c}6.09 \\
-\end{array}$ & $\begin{array}{c}3.73 \\
(19-21) \%\end{array}$ & $\begin{array}{c}6.09 \\
-\end{array}$ & $\begin{array}{c}5.20 \\
(7-8) \%\end{array}$ & $\begin{array}{c}3.73 \\
(20-22) \%\end{array}$ \\
\hline
\end{tabular}

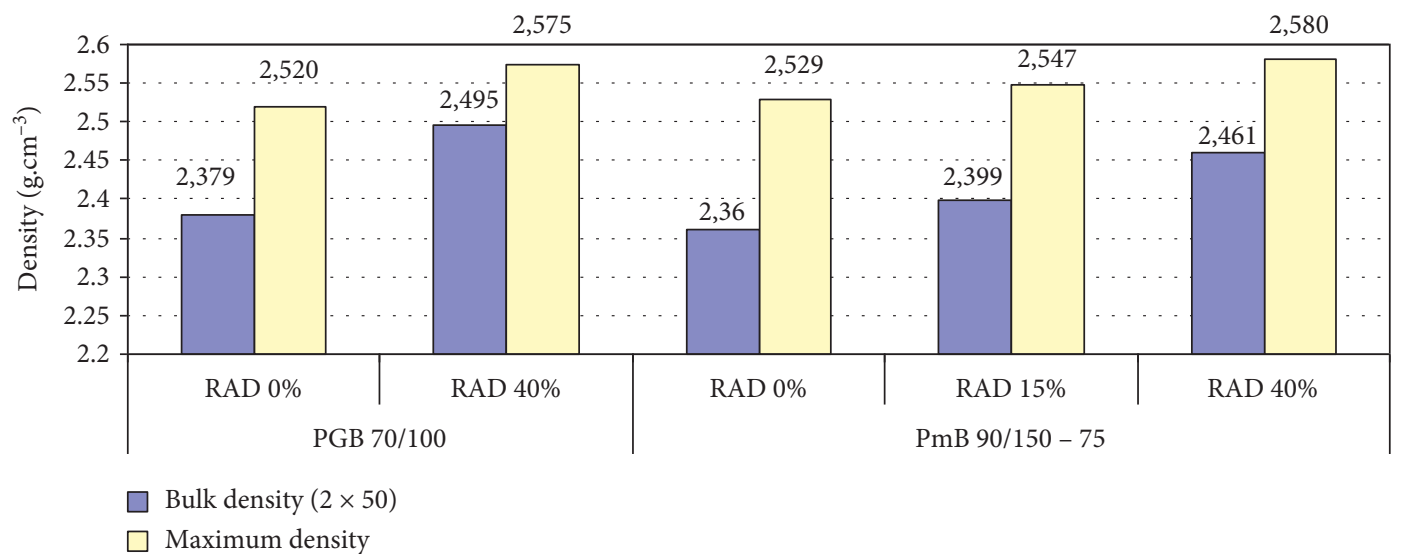

FIGURE 10: Bulk densities for asphalt mixtures with different ratios of RA containing PMB.

$25 \mathrm{~mm}$ deep crack) and $38,689 € / \mathrm{m}^{2}$ of patching (calculated as patching of a pothole with 10 litre volume), then, considered the area of damaged pavement surface, costs of periodic maintenance for $1 \mathrm{~m}^{2}$ of motorway pavement are $0.06 € / \mathrm{m}^{2}$ of carriageway in the first year after initiation (due to SD progression in given year due to delay caused by contracting) and $0.04 € / \mathrm{m}^{2}$ of carriageway for subsequent years; this is seen in Table 7 .

What follows is the obligatory question: "Does the increase in periodic maintenance costs for higher RA content surfacing justifies the procurement cost savings?" A short market survey estimated that prices are fluctuating around $80 € /$ ton for SMA $11 \mathrm{PMB}$ compacted mixture. For the bulk density of $0.0944 \mathrm{ton} / \mathrm{m}^{3}$, this equals to $7.55 € / \mathrm{m}^{2}$ of $40 \mathrm{~mm}$ surfacing layer. Bulk density for the same mixture with $15 \%$ RA content is $0.096 \mathrm{~m}^{3}$ and for $40 \%$ RA content $0.0984 \mathrm{~m}^{3}$. Using RA decreases the mixture procurement price; for $15 \%$ RA content the market survey yield $8 \%$ reduction, i.e. 7.06
$€ / \mathrm{m}^{2}$ (savings of $0.49 € / \mathrm{m}^{2}$ ); and for $40 \%$ RA content $22 \%$ reduction, i.e. $6.30 € / \mathrm{m}^{2}$ (savings of $1.25 € / \mathrm{m}^{2}$ ). The material costs are the sole difference in the procurement price as the layer laying costs remain the same, whether RA content is used or not. Note also that all listed prices are VAT excluded. For other mixtures, estimated financial savings expressed in percentage are shown in Table 8 , and bulk densities needed for recalculation of material per volume of paving layer are shown in chart in Figure 10. It is safe to assume that interpolation and extrapolation in Table 8 and Figure 10 would result in reliable data for both financial savings and bulk densities for other mixture ratios.

Based on this case study, it is safe to say that despite increased periodic maintenance costs, the use of bituminous mixtures with RA containing PMB is still an economically viable alternative, and road administrators should be encouraged in their use not only from an ecological point of view but also for economic reasons. 


\section{Conclusions}

\subsection{Material Laboratory Testing Conclusions}

(i) Mixtures with RA containing PMB have a better performance concerning rutting, and the ratio of RA increased resistance to rutting [28].

(ii) Mixtures with RA containing PMB have a higher stiffness modulus compared to the mixtures without RA. This makes these mixtures more brittle at low temperatures, and the advantage to this would be a higher bearing capacity. Ideal balance between stiffness and chance of brittleness varies for different temperature conditions.

(iii) Mixture with 40\% RA containing PMB showed worse fatigue parameters compared to the mixture without RA containing PMB. On the contrary, the mixture with virgin $\mathrm{PMB}$ was the most fatigue resistant. The addition of RA decreased fatigue performance.

The data gained in the material laboratory testing were used in a case study, and the conclusions are presented as follows:

(i) Due to the increased stiffness modulus, motorway pavement with SMA wearing course containing $15 \%$ and $40 \%$ RA PMB had after $4.39 \times 10^{6}$ equivalent standard axle loads increased resiliency to plastic deformation resulting in $3 \mathrm{~mm}$ and $7 \mathrm{~mm}$ difference in RUT, respectively. The value for the $0 \%$ RA PMB wearing course was $18 \mathrm{~mm}$, i.e., RUT was $15 \mathrm{~mm}$ for $15 \%$ RA PMB and $11 \mathrm{~mm}$ for $40 \%$ RA $\mathrm{PMB}$. This is a significant reduction since critical levels of RUT on motorway pavements are considered around $20 \mathrm{~mm}$.

(ii) The initiation of cracking takes place 2 and 7 years earlier for the scenarios with $15 \%$ and $40 \%$ of RA material, respectively. The cracking initiation for the $0 \%$ RA PMB wearing course was 17 years, i.e., 15 and 10 years respectively for $15 \%$ and $40 \%$ RA PMB content, respectively. This is also significant; however, surface distress can be effectively countered with periodic maintenance.

(iii) Use of RA PMB material increases the periodic maintenance cost of pavement; in return, it effectively prolongs the life expectancy of a pavement by postponing more expensive repair and reconstruction actions.

(iv) Use of RA PMB is economically viable due to lower procurement price of mixtures with RA PMB content and prolonged life expectancy, which, in combination, outweigh the increase in periodic maintenance costs.

\section{Data Availability}

The raw and processed data required to reproduce these findings are availabale to download from https://www. uschovna.cz/sk/zasilka/REIK32DA6IGH27XT-2I7/.

\section{Conflicts of Interest}

The authors declare that there are no conflicts of interest regarding the publication of this paper.

\section{Acknowledgments}

The research and publication of this article are funded by the employer of the research team: University of Zilina.

\section{References}

[1] K. R. Hansen and A. Copeland, Annual Asphalt Pavement Industry Survey on Recycled Materials and Warm-Mix Asphalt Usage: 2009-2012. No. IS-138, National Asphalt Pavement Association, Lanham, MD, USA, 2013.

[2] J. Komacka, E. Remisova, and F. Schlosser, "Asphalt mixtures using reclaimed asphalt containing polymer modified binder, possibilities for high-quality recyling of polymer modified asphalt: RECYPMA,” Deliverable Nr.4.1, Report, 2013.

[3] A. Liphardt and P. Radziszewski, "Analysis of viscoelastic properties of binders recovered from bituminous mixtures containing addition of reclaimed asphalt pavement," Roads and Bridges-Drogi i Mosty, vol. 18, no. 1, pp. 39-50, 2019.

[4] S. Sreedhar and E. Coleri, "Effects of binder content, density, gradation, and polymer modification on cracking and rutting resistance of asphalt mixtures used in Oregon," Journal of Materials in Civil Engineering, vol. 30, no. 11, Article ID 04018298, 2018.

[5] M. J. Riley and C. R. Bennett, Specifications for the HDMRoad Deterioration Model-Preliminary, Second and Third Drafts, ISOHDM, Birmingham, UK, 1995 and 1996.

[6] Y. Gao, Q. Guo, Y. Guo, P. Wu, W. Meng, and T. Jia, "Investigation on reinforced mechanism of fiber reinforced asphalt concrete based on micromechanical modeling," Advances in Materials Science and Engineering, vol. 2017, Article ID 4768718, 12 pages, 2017.

[7] European Committee for Standardization, European Standard EN 12697-35+A1, Bituminous Mixtures -Test Methods for Hot Mix Asphalt-Part 35: Laboratory Mixing, European Committee for Standardization, Brussels, Belgium, 2007.

[8] European Committee for Standardization, European Standard EN 12697-8, Bituminous Mixtures -Test Methods for Hot Mix Asphalt-Part 8: Determination of Void Characteristics of Bituminous Specimens, European Committee for Standardization, Brussels, Belgium, 2003.

[9] European Committee for Standardization, European Standard EN 12697-5, Bituminous Mixtures -Test Methods for Hot Mix Asphalt-Part 5: Test Methods for Hot Mix Asphalt. Part 5: Determination of the Maximum Density, European Committee for Standardization, Brussels, Belgium, 2012.

[10] European Committee for Standardization, European Standard EN 12697-6, Bituminous Mixtures -Test Methods for Hot Mix Asphalt-Part 6: Determination of Bulk Density of Bituminous Specimens, European Committee for Standardization, Brussels, Belgium, 2012.

[11] European Committee for Standardization, European Standard EN 12697-12, Bituminous Mixtures -Test Methods for Hot Mix Asphalt-Part 12: Determination of the Water Sensitivity of Bituminous Specimens, European Committee for Standardization, Brussels, Belgium, 2008.

[12] European Committee for Standardization, European Standard EN 12697-22, Bituminous Mixtures -Test Methods for Hot Mix Asphalt-Part 22: Wheel Track, European Committee for Standardization, Brussels, Belgium, 2007. 
[13] European Committee for Standardization, European Standard EN 13108-20, Bituminous Mixtures-Material Specifications-Part 20: Type Testing, European Committee for Standardization, Brussels, Belgium, 2008.

[14] European Committee for Standardization, European Standard EN 12697-26, Bituminous Mixtures -Test Methods for Hot Mix Asphalt-Part 26: Stiffness, European Committee for Standardization, Brussels, Belgium, 2012.

[15] European Committee for Standardization, European Standard EN 12697-24, Bituminous Mixtures -Test Methods for Hot Mix Asphalt-Part 24: Resistance to Fatigue, European Committee for Standardization, Brussels, Belgium, 2012.

[16] European Committee for Standardization, European Standard EN 12697-46, Bituminous Mixtures. Test Methods for Hot Mix Asphalt. Low-Temperature Cracking and Properties by Uniaxial Tension Tests, European Committee for Standardization, Brussels, Belgium, 2012.

[17] Z. Zhou, X. Y. Gu, J. W. Jiang, F. J. Ni, and Y. X. Jiang, "Fatigue cracking performance evaluation of laboratoryproduced polymer modified asphalt mixture containing reclaimed asphalt pavement material," Construction and Building Materials, vol. 216, pp. 379-389, 2019.

[18] J. Mikolaj, L. Remek, and M. Macula, "Asphalt concrete overlay optimization based on pavement performance models," Advances in Materials Science and Engineering, vol. 2017, Article ID 6063508, 10 pages, 2017.

[19] J. Mikolaj, L. Remek, and M. Kozel, "Optimization of life cycle extension of asphalt concrete mixtures in regard to material properties, structural design, and economic implications," Advances in Materials Science and Engineering, vol. 2016, Article ID 6158432, 9 pages, 2016.

[20] J. Mikolaj, F. Schlosser, L. Remek, and A. Chytcakova, "Asphalt concrete mixtures: requirements with regard to life cycle assessment," Advances in Materials Science and Engineering, vol. 2015, Article ID 567238, 7 pages, 2015.

[21] B. Leitner, M. Decky, and M. Kovac, "Road pavement longitudinal evenness quantification as stationary stochastic process," Transport, vol. 34, no. 2, pp. 195-203, 2019.

[22] W. D. O. Paterson, Road Deterioration and Maintenance Effects, World Bank Publications, Washington DC, USA, 1987.

[23] T. Watanada, C. G. Harral, and W. D. O. Paterson, "The highway design and maintenance standards model," vol. 1, The World Bank, John Hopkins University Press, Washington DC, USA, 1987.

[24] NDLI, Modelling road user effects in HDM-4, final report. Asian development bank project RETA 5549. International study of highway development and management tools, N.D. Lea International, Vancouver, BC, USA, 1995.

[25] Road Association AIPCR, The Highway Development and Management Series, Volume 4 Analytical Framework and Model Description, 2006.

[26] E. Remisova, M. Decky, M. Mikolas et al., "Design of road pavement using recycled aggregate, World multidisciplinary Earth sciences symposium (WMESS 2016), PTS 1-4 book series," IOP Conference Series-Earth and Environmental Science, vol. 44, Article ID 022016, 2016.

[27] G. Morosiuk, Specifications Fr the HDM-4 Road Deterioration Model-Fourth, Fifth, Sixth, Seventh and Eight Drafts, ISOHDM, Birmingham, UK, 2006.

[28] C. Brovelli, M. Crispino, J. Pais, and P. Pereira, "Using polymers to improve the rutting resistance of asphalt concrete," Construction and Building Materials, vol. 77, pp. 117-123, 2015. 


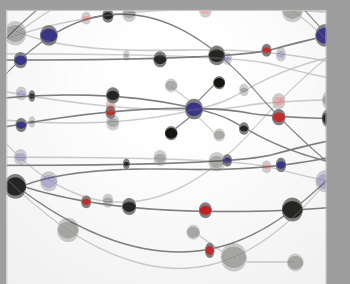

The Scientific World Journal
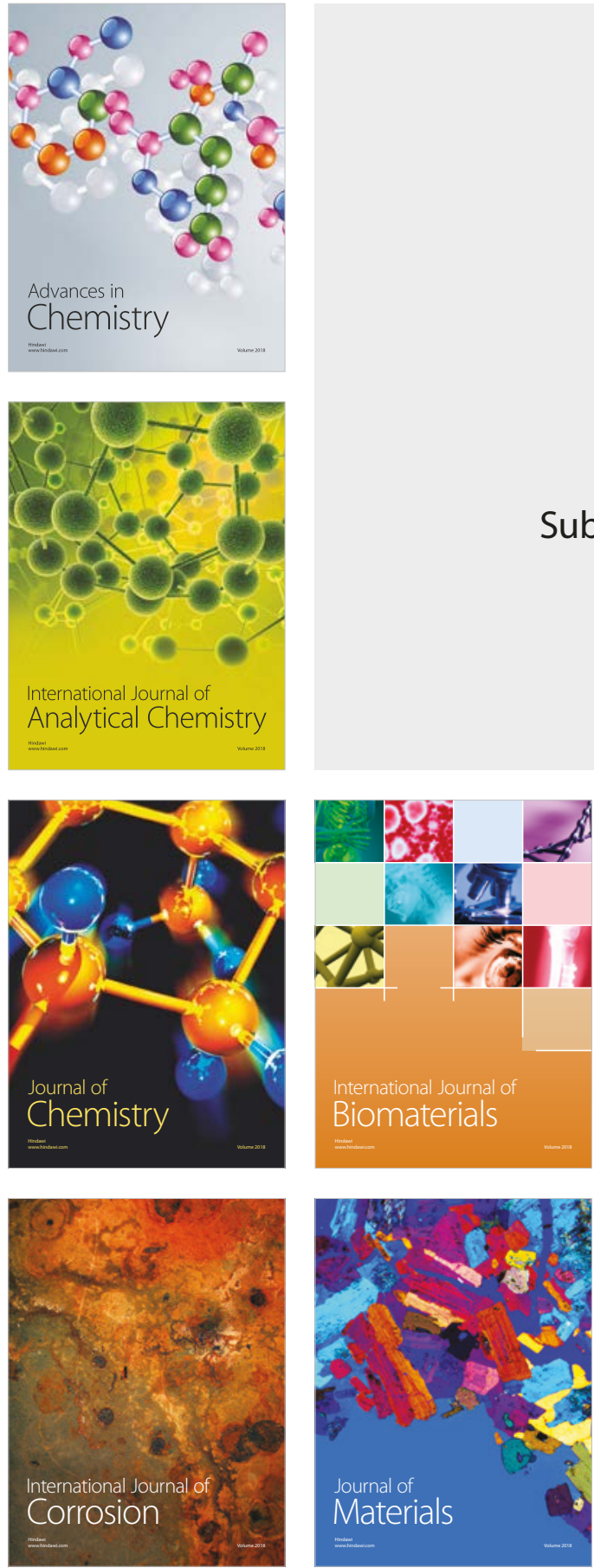

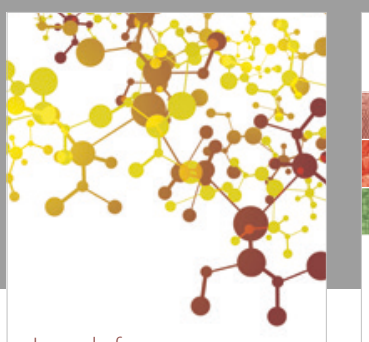

Journal of

Applied Chemistry
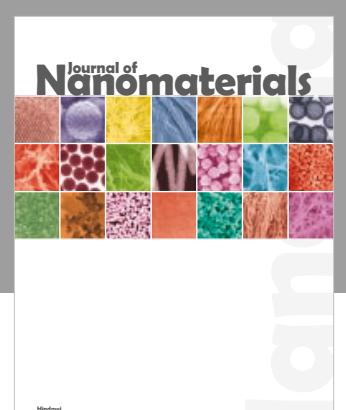

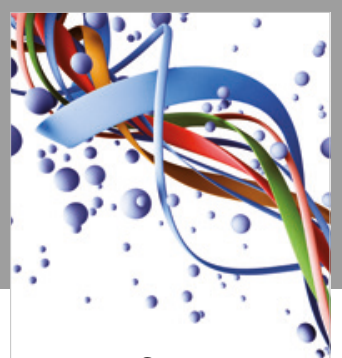

Scientifica

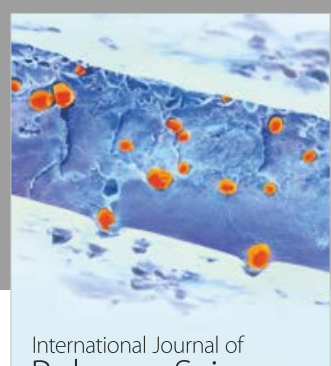

Polymer Science

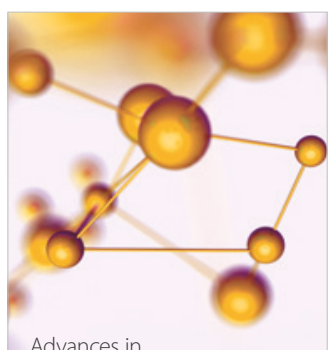

Physical Chemistry
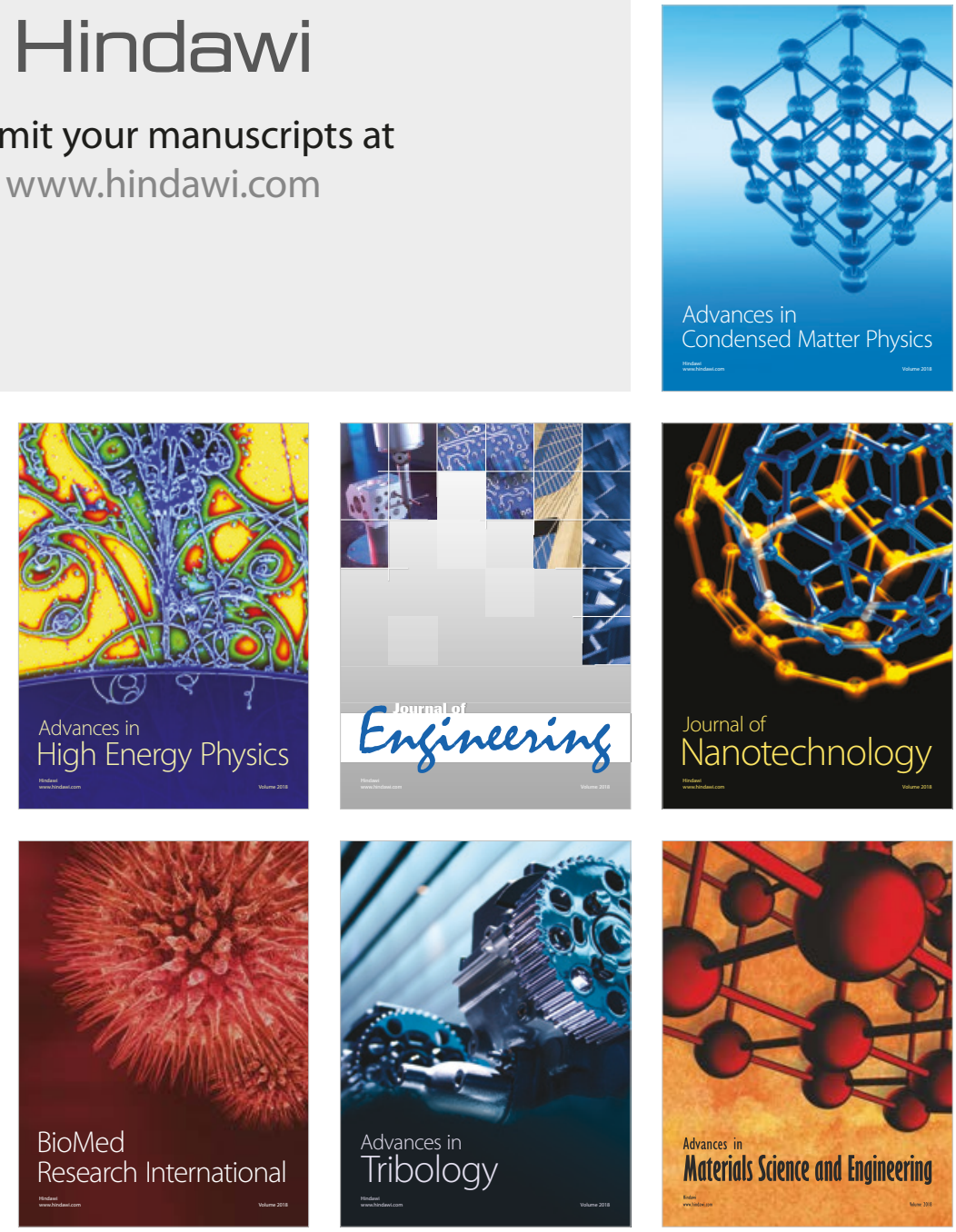